\title{
Ideological Consumerism in Colombian Elections, 2015: Links Between Political Ideology, Twitter Activity, and Electoral Results
}

\author{
Juan C. Correa, PhD, and Jorge E. Camargo, $\mathrm{PhD}^{2}$
}

\begin{abstract}
Propagation of political ideologies in social networks has shown a substantial impact on voting behavior. Both the contents of the messages (the ideology) and the politicians' influence on their online audiences (their followers) have been associated with such an impact. In this study we evaluate which of these factors exerted a major role in deciding electoral results of the 2015 Colombian regional elections by evaluating the linguistic similarity of political ideologies and their influence on the Twitter sphere. The electoral results proved to be strongly associated with tweets and retweets and not with the linguistic content of their ideologies or politicians' followers in Twitter. Finally, suggestions for new ways to analyze electoral processes are discussed.
\end{abstract}

Keywords: Twitter, Colombian elections, ideological consumerism

\section{Introduction}

D UE TO THE power that social networks have for promoting political mobilization and participation, politicians are using these tools to communicate their ideas and change "political consumerism". .

Political consumerism consists of turning the market into a site for politics and ethics, as consumer choices reflect personal attitudes and purchases are informed by ethical or political assessment of business and government practice. ${ }^{2}$ An example of this occurred when the French government opposed the approval of a UN Security Council resolution that allowed the use of military force against Iraq in 2003. By that time, sales of French wines dropped in a portion of United States restaurants and in some shops, sales of French cheeses were eliminated, whereas in some food outlets "French fries", were rechristened as "Freedom fries"; a trend that shows how Americans opposed the French position, not by taking the streets to express their views, but by using their purchasing power for spoiling French exports. ${ }^{1}$

Political consumerism can be also understood as the socalled "ideological consumerism" roughly defined as the study of the interacting psycho-socio-cultural processes when an individual or group prefers, fosters, and spreads their beliefs and quotidian practices that mediate commercial exchange. ${ }^{3}$ We use the concept of political consumerism as a synonym of ideological consumerism since they both manifest linguistically through spoken or written discourses with consistent behaviors that can be observed in the real-world and the social networks as well. An approach of this kind allows the researcher to collect a sample of political messages like the ones that can be found in political campaigns through Twitter or Facebook and scrutinize the beliefs that are associated with the ideological consumerism by employing analytical techniques of natural language use that aim to get computers to perform useful tasks involving human language, like improving human-to-human communication. In this work we aim to offer a novel analysis of Colombian elections based on this approach.

\section{Studying Ideological Consumerism Within Electoral Processes in Social Networks}

A distinctive feature of ideological consumerism is that its linguistic manifestation goes along with consistent behaviors that allow the identification of group's beliefs in the realworld and the digital social networks as well. Several studies illustrate this fact. Yet, mentions to the concept of ideological consumerism are absent. For example, Conover et al. ${ }^{4}$ observed in the 2010 United States of America congressional elections that right-leaning Twitter users exhibited greater levels of political activity, a more tightly interconnected

\footnotetext{
${ }^{1}$ Facultad de Psicología, Fundación Universitaria Konrad Lorenz, Bogotá, Colombia.

${ }^{2}$ Facultad de Matemáticas e Ingenierías, Fundación Universitaria Konrad Lorenz, Bogotá, Colombia.

(C) Juan C. Correa and Jorge E. Camargo 2017; Published by Mary Ann Liebert, Inc. This Open Access article is distributed under the terms of the Creative Commons Attribution Noncommercial License (http://creativecommons.org/licenses/by-nc/4.0/) which permits any noncommercial use, distribution, and reproduction in any medium, provided the original author(s) and the source are credited.
} 
social structure, and a communication network topology that facilitated the rapid and broad dissemination of political information. In these same elections Bond et al. ${ }^{5}$ observed that the messages delivered to 61 million Facebook users directly influenced political self-expression, information seeking, and real-world voting behavior on the users who received them and the users' friends, and friends of friends. They also found that the effect of social transmission on real-world voting was greater than the direct effect of the messages themselves, and nearly all the transmission occurred between close friends who were more likely to have a face-to-face relationship, showing that strong ties are instrumental for spreading both online and real-world behavior in social networks.

The available evidence shows that the ideological consumerism, the political participation in digital social networks, and social processes like influence and persuasion are strongly connected to one another. For example, Gruzd and Roy ${ }^{6}$ observed during the 2011 Canadian Federal Election that Twitter users tended to cluster around shared political views even though they eventually interacted with other users of opposing ideologies. Furthermore, it has been noticed that the online social structure of a political party was strongly related to its ideology, and the degree of connectivity across two parties grew when they were close in the ideological space of a multiparty system like the Swiss one. ${ }^{7}$ Needless to say that political participation in social networks also relates with voters' feelings and attitudes since these can be influenced and/or persuaded by politicians' messages. In fact, Maruyama et al. ${ }^{8}$ observed that participants' average feeling and recall toward political candidates did not depend on Twitter activity which, in contrast, proved to be important for vote choice, in such a way that people who actively tweeted changed their voting choice to reflect the prevailing sentiment on Twitter. The explanation of these results is yet to be developed, although two recent approaches have shed some light. One possible explanation is related with the significant contribution that Twitter opinion leadership has on individuals' involvement in political processes ${ }^{9}$; that is, influential Twitter users generate more political involvement among their followers. Another possible explanation is that political leaders can persuade their followers directly not by their influence, but by sharing their attitudes regarding policy issues, attributions regarding the leader's qualities, and the subsequent voting behavior. ${ }^{10}$ These explanations have not been tested on recent results of the 2013 elections of the Italian parliament, ${ }^{11}$ where it was noticed that the activity on Twitter in terms of volume (total tweets) and change in time provided a very good proxy of the official electoral results. However, it is clear that voting behavior, as a behavioral manifestation of ideological consumerism, is influenced by the political messages that are spread in social networks and this allows us to regard political messages and Twitter activity as key factors that play some role in defining electoral results. Yet, given the fact that such messages reflect divergent ideologies, it might be relevant knowing if there are linguistic similarities among their contents; and if so, which of them captures more votes and why. Here lies the importance of analyzing natural language use in social networks when politicians are in democratic campaign and its influence on voting behavior.

\section{Analyzing the Ideology and the Natural Language Use of Politicians in Twitter}

There are very good reasons that justify the need of analyzing the natural language use in political texts. As illustrated by Grimmer and Stewart ${ }^{12}$ the massive costs of analyzing even moderately sized text collections have hindered their use in scientific research and here lies the promise of the analysis of natural language use that substantially reduces the costs of analyzing large collections of texts. In addition, this technique amplifies the ability of researchers in conducting rigorous inquiries of political texts by allowing them to choose among a plethora of models for text organization, text classification, etc. Finally, the analysis of natural language use requires the researcher to provide some sort of validation to test whether the findings are robust or not. According to some scholars, ${ }^{12}$ the use of this technique will be the standard approach in political and related sciences since politics and political conflicts often occur in the written and spoken word.

A convenient way to analyze the natural language use of politicians in Twitter can be done through the so-called word count strategies. ${ }^{13,14}$ These strategies were developed inside the interdisciplinary field known as "natural language processing" or "computer linguistics" that aims to get computers to perform useful tasks with human language, like improving human-to-human communication. ${ }^{15}$ In fact, such strategies have served as the basis for developing recent software that have been rewarded by the Society for Political Methodology (http://polmeth.wustl.edu/) to enhance the way of doing research in political and social sciences.

The analysis of the ideology and the natural language use of politicians in Twitter begins with the identification of tweets whose content is related with political campaigns in the preceding weeks of the elections. All these tweets have to be merged in a single document that will be decomposed in their staple linguistic components known as "corpus", 16 According to Sudhof ${ }^{17}$ a corpus vocabulary of size $n$ can represent a "bag of words" of document $i$ as an ndimensional vector $v_{i}$, where each component represents one word in the document. The value of dimension $j$ of document vector $v_{i}$ depends on the importance of the word $j$ in document $i$, being the importance quantified by contrasting the term frequency with the inverse document frequency which formalizes the idea that a rare term or word has higher information content than expected terms like prepositions, articles, and pronouns. Formally, a document vector is expressed as follows,

$$
\mathrm{x}_{\mathrm{i}}=\left(\mathrm{x}_{1, \mathrm{i}}, \mathrm{x}_{2, \mathrm{i}}, \mathrm{r} \mathrm{x}_{3, \mathrm{i}}, \ldots, \mathrm{x}_{\mathrm{t}, \mathrm{i}}\right)
$$

and

$$
\mathrm{x}_{\mathrm{t}, \mathrm{i}}=\mathrm{tft} \cdot \log |\mathrm{D}| /|\{\mathrm{t} \in \mathrm{i}\}|
$$

where $t f t$ is the term frequency of the word $t$ in the document $i,|D|$ is the number of documents in the collection, and $\log |D| /\{t \in i\} \mid$ is the inverse frequency of the documents that contain $t$. At the end of this process the so-called "termdocument matrix" is built. This matrix returns the words that occur at least one time in any of the documents that constitute the collection of tweets of each politician. Representing 
the collection of tweets as a vector in the Euclidean space allows the evaluation of its linguistic similarity with a second collection of tweets, both reflecting the ideology of each politician. ${ }^{14}$ This linguistic similarity is then estimated by the Euclidean distance between document vectors. ${ }^{17}$ Although this procedure does not take into account the subtleties of language (like sarcasm or irony) that are commonly used in politics, ${ }^{18}$ it offers a suitable quantitative metric for evaluating the similarity between two politicians representing different political ideologies. ${ }^{19}$

Since Colombian ideological parties have witnessed a complex series of reforms that have promoted the creation of new parties, ${ }^{20}$ their traditional differentiation in terms of the "left-right" spectrum with the "Conservative Party" and the "Liberal Party" at the center stage ${ }^{21}$ is neither useful nor appropriate because of the substantial increase of new political parties. Accordingly, we propose another classification that reflects these recent changes in Colombian parties; that of traditional parties (e.g., "Partido Conservador Colombiano"), independent parties (e.g., "Movimiento Alternativo Indígena y Social"), or alliances between them (e.g., "Alianza entre Partido Conservador y Partido de la U"). If political ideology plays an important role in influencing voting behavior, as it has been previously shown in other countries, ${ }^{6,7,22,23}$ we might hypothesize that in the case of Colombian regional elections the linguistic similarities between politicians of the same ideological affiliation should be higher than the similarities they share with politicians of other ideologies, and these similarities will show a non-nil and a statistically significant relationship with the amount of votes that politicians received. In other words, we could expect that the act of sharing a political ideology would serve as a mechanism for communicating a well-defined set of words and ideas related with such an ideology.
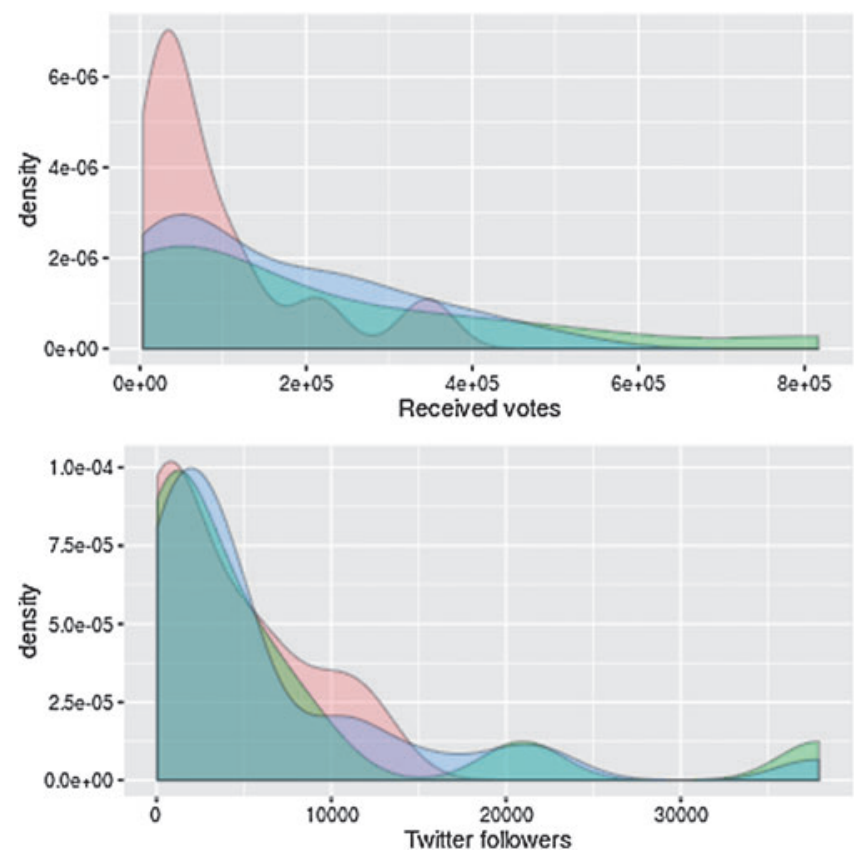

Our theoretical approach also allows us to establish a second hypothesis on the relationship between politicians' Twitter activity and electoral results. If politicians can exert their influence by increasing their Twitter activity in terms of the number of followers, tweets and re-tweeted messages, ${ }^{24-26}$ then we might hypothesize that the statistical behavior of these metrics will not only be different depending on the political ideology of the politician, but they will also be associated with electoral results, with more received votes for politicians with more Twitter activity.

\section{Methodology}

Two data sets were built for the analysis. The first was composed by the official electoral results of the last democratic elections in Colombia, held in October 25, 2015. In these elections 32 new governors had to be elected across the country (one in each Colombian department). Ad hoc queries were designed and used with the software "Import.io" (https://import.io/) for retrieving the official results from the elections web page (http://colombia.com/elecciones/2015/ regionales/). In querying these results we obtained a list containing the names of political contenders, their declared political affiliation, as well as the amount of received votes in their departments. Political abstention was 39.69 percent, a little bit lower than previous ones. ${ }^{27}$ The second data set was built with the "twitteR" package which was developed to mine short messages in this social network through the $\mathrm{R}$ environment. ${ }^{28}$ This data set was composed by the tweets spread by Colombian politicians during the preceding 3 weeks of the elections (between October 1, 2015 and October 24, 2015). A total of 140 candidates participated in the elections and 52 of them showed an active Twitter use for promoting their own political campaign. Thus, our sample represents $37.14 \%$ of Colombian politicians who participated
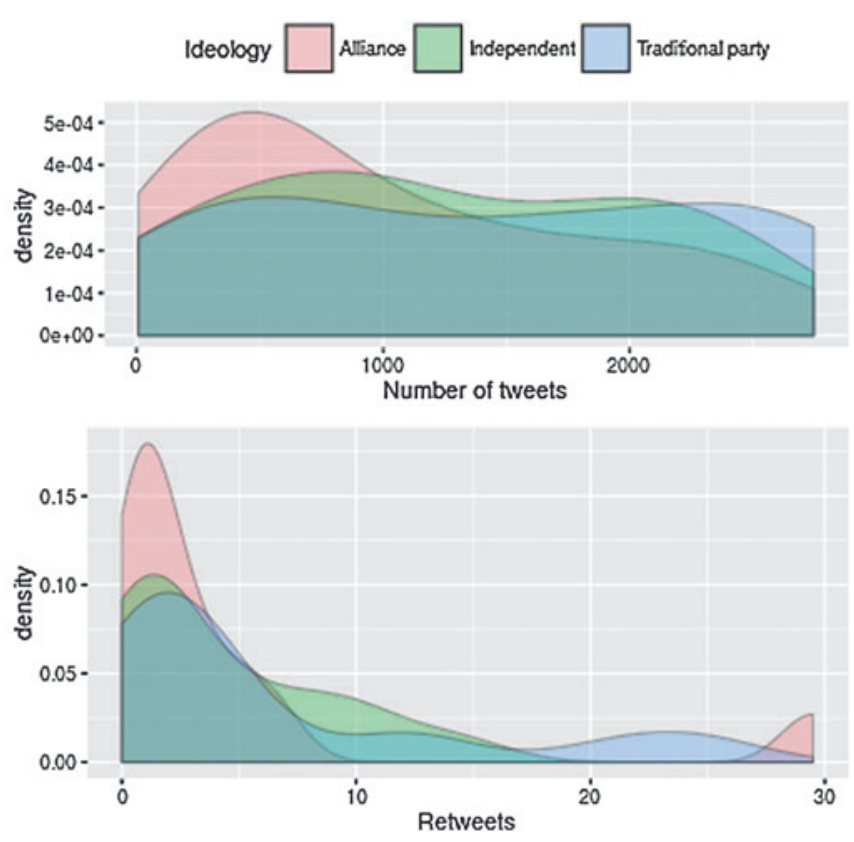

FIG. 1. Statistical distributions of Received votes, Twitter followers, and Number of tweets and retweets of Colombian politicians running for governors in the Colombian regional elections. 
FIG. 2. Statistical distributions of linguistic similarity between pairs of Colombian political ideologies.

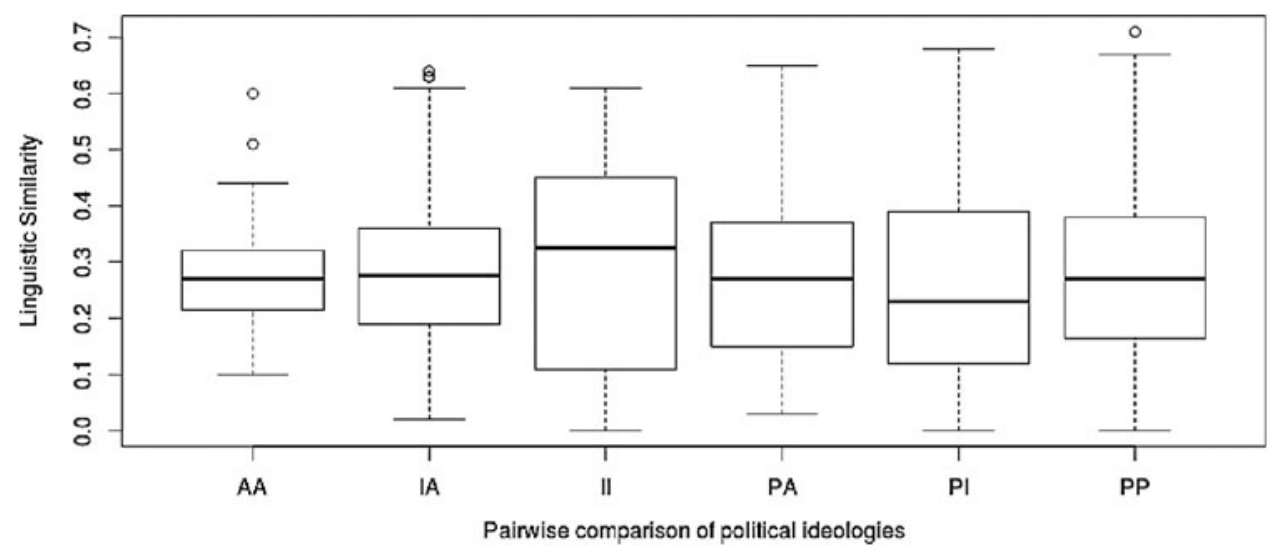

in the elections for new governors. Tweets of each politician were structured as a corpus in a single text document. We then obtained 52 corpora (one for each politician) containing all the tweets that were communicated through this social network. All these tweets were written in Spanish and given the fact that they can include special characters such as HTML tags, punctuation marks, mentions (Twitter usernames preceded by the "@”), and hashtags (thematic words preceded by the "\#”), we removed these characters, and preserved word accents because of their relevance in Spanish language. We followed a two-step procedure for textcleaning purposes. In the first step we applied the so-called "stemming" procedure, consisting in reducing inflected words to their root word. For example, the Spanish words "gobernación," "gobernaciones," "gobernador," and "gobernadores" were reduced to the stem word "gobern." The second step consisted in removing the so-called "stop words" by using the stop words list included in the "koRpus" package. These words were removed because of their high frequency in natural language use ${ }^{29}$ and its resulting little contribution in the linguistic representation of a text document. A total of 69,202 tweets were processed following Equations (1) and (2). Each corpus was also accompanied by the politician's username in Twitter, the amount of Twitter followers for each tweet, and the number of retweets received by each politician's tweet. The political ideology of each text document was manually assigned according to the affiliation of the politician and its membership to one of the three categories proposed at the final part of the previous section. The linguistic similarity between pairs of Colombian political ideologies was calculated through the Euclidean distance between document vectors.

\section{Results}

Figure 1 shows the statistical distributions of received votes, Twitter followers, and the number of tweets and its retweets according to political ideologies of politicians running for governors in the Colombian regional elections. Regardless of their ideology, politicians showed no statistical differences in the amount of received votes $(F=1.23 ; d f=2$; $p=0.301)$, the amount of tweets they propagated $(F=0.812$; $d f=2 ; p=0.451)$, the average number of re-tweeted messages $(F=0.489 ; d f=2 ; p=0.616)$, and the number of Twitter followers they had during their campaign $(F=0.398$; $d f=2 ; p=0.674)$.
Figure 2 depicts the statistical distribution of linguistic similarity between pairs of texts (tweets collection) representing Colombian political ideologies; namely, the similarity between candidates both belonging to either traditional parties (PP), independent parties (II), alliances between parties (AA), or any other combination between them. The comparison also reveals nonsignificant statistical differences $(F=1.231 ; d f=5 ; p=0.292)$, since their representative candidates tend to use the same set of words for promoting their own electoral campaign in the preceding 3 weeks of the Colombian regional elections (Table 1).

Review of the Shapiro-Wilk test for normality suggests that neither the received votes $(S W=0.808 ; d f=52 ; p<0.001)$ nor the number of Twitter followers $(S W=0.679 ; d f=52$; $p<0.001)$, neither the number of tweets $(S W=0.921 ; d f=52$; $p=0.002)$, nor the number of retweets $(S W=0.714 ; d f=52$; $p<0.001)$ showed a normal symmetric distribution. Thus, we evaluate the statistical nonparametric association between these metrics through the Spearman's rank correlation coefficient (Fig. 3).

For political alliances none of the Twitter metrics, except the one between Retweets and Twitter followers ( $\rho=0.682$; $p=0.021$ ), showed a significant association. All of these metrics showed significant associations for independent parties $(\rho \geq 0.627 ; p \leq 0.05)$, whereas for traditional parties all these metrics also showed significant associations ( $\rho \geq$ $0.458 ; p \leq 0.05$ ), except those between the number of tweets with received votes and the number of tweets with retweets. To clarify which of these factors exerted a major role in deciding electoral results (quantified by the received votes

Table 1. Top-30 Most Frequent Words of Colombian Politicians' Campaign

\begin{tabular}{lclclc}
\hline Word & Freq & \multicolumn{1}{c}{ Word } & Freq & Word & Freq \\
\hline gobern & 50 & Candidat & 43 & Gran & 41 \\
apoy & 49 & mejor & 43 & Asi & 41 \\
vot & 49 & Hoy & 43 & propuest & 41 \\
octubr & 48 & Respald & 42 & Buen & 41 \\
campa & 47 & Invit & 42 & Trabaj & 41 \\
graci & 45 & Hac & 42 & Polit & 40 \\
part & 45 & Municipi & 42 & Recib & 40 \\
gobiern & 45 & Segu & 41 & Gent & 40 \\
comun & 44 & departament & 41 & Tod & 40 \\
Día & 44 & Salud & 41 & acompa & 39 \\
\hline
\end{tabular}



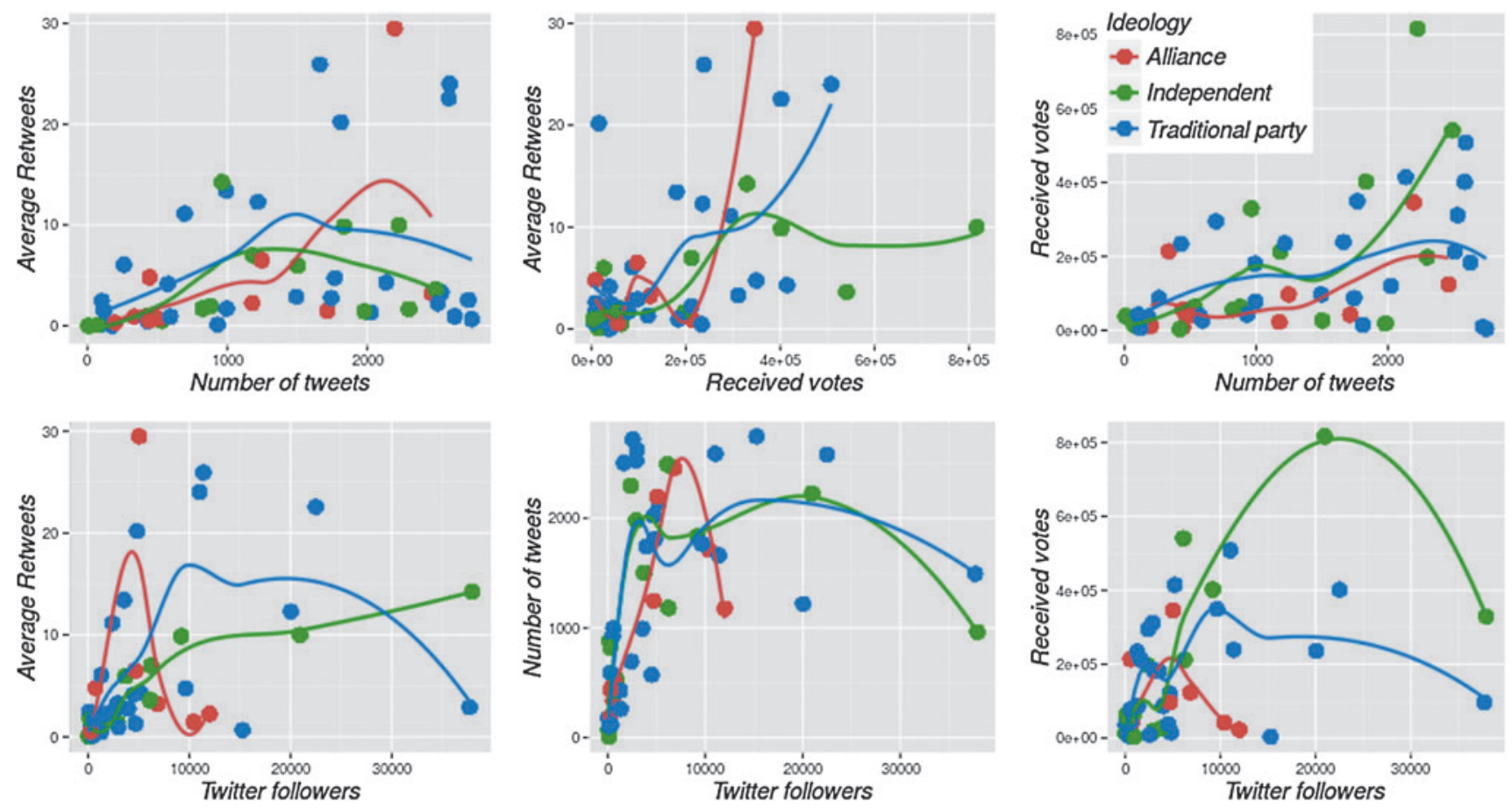

FIG. 3. Scatterplots of received votes and Twitter metrics by political ideology in the 2015 Colombian regional elections.

for each candidate), we finally test their multivariate association with a Kernel regression model. ${ }^{30}$ The results show an acceptable goodness of fit $\left(R^{2}=0.787 ; p \leq 0.001\right)$ revealing that the received votes proved to be more associated with the number of retweets (Bandwidth $=4.29 ; p \leq 0.01$ ) and tweets (Bandwidth $=633.06 ; p=0.09$ ). Neither the similarity of ideological content (Bandwidth $=161148.3$; $p=0.08$ ) nor the number of followers in Twitter (Bandwidth $=49,419,488,164 ; p=0.37$ ) proved to be important factors in relation to the received votes.

\section{Discussion}

Our aim in this article was to offer a different analysis on the relationship between Twitter use in election campaigns and electoral results with the Colombian case, although our method can be used elsewhere. Compared with recent literature reviews that have shown the use of Twitter in election campaigns, ${ }^{31}$ our study offers the following couple of contributions: (1) a theoretical approach for testing the hypothesis that the ideological consumerism allows politicians differentiate from others in terms of linguistic speeches and Twitter activity, (2) a clear procedure for data collection that can be easily followed by social and political scientists.

Our results showed that Colombian politicians tend to use the same set of words, conveying a rather homogeneous message that prevents their differentiation from contenders of other ideologies. Although with these results we are forced to reject the hypothesis that ideological consumerism allows Colombian politicians to differentiate themselves from others, it is premature to completely discard this hypothesis solely on the basis of our results. Further studies in other countries and societies should test this same hypothesis and contribute with the theoretical progress of this field that is still in an early phase. ${ }^{31}$ In any case, the conclusion that regardless their ideology, politicians in election campaigns convey an homogeneous message that prevents their differentiation from others has not been found in any previous research of Colombian electoral studies ${ }^{19,20,32-34}$ or in $\mathrm{Ca}$ nada, ${ }^{6}$ Switzerland, ${ }^{7}$ Italy, ${ }^{11}$ Germany, ${ }^{35}$ United States of America, ${ }^{36}$ Spain, ${ }^{37}$ India, ${ }^{38}$ or elsewhere.

Our results also showed that the election results in the Colombian campaign were more associated with the amount of retweets and tweets than with the ideological content similarity or Twitter followers. Previous studies conducted during the United States of America 2012 electoral campaign $^{36}$ have found that Twitter users were consistent in their actions of tweeting and retweeting about political issues and similar users tended to be retweeted by similar audiences. Our results, however, are contrasting with regard to what is known about influence in Twitter. ${ }^{22}$ The number of retweets reflects the ability of a Twitter user to generate content with pass-along value. Yet, given the fact that Colombian politicians employed a quite homogeneous set of words for promoting their own political campaign, it is rather paradoxical that the fact that some politicians obtain more retweets than others when they all convey a standard message in political campaign. In disentangling this paradoxical fact, we suggest two further analyses. First, it might be important to evaluate if the probability of retweeting a tweet has to do with the simplicity of the message instead of the ideological content itself. An alternative analysis might evaluate whether the combination of socially sensitive words (detected as bigrams, trigrams, or n-grams) increases the odds of retweeting short messages. Actually, we tackle this problem in a forthcoming article that deals with the use of a computationally efficient inverse regression Bayesian method ${ }^{39}$ for analyzing tweet propagation in election campaigns. 


\section{Acknowledgments}

The authors wish to express their gratitude to anonymous reviewers for their useful observations on previous drafts of the article. They also thank Professors Silvana Dakduk, Diana E. Forero, and Gustavo García for comments and advice. They thank Diana Onofre for her support in identifying Twitter user accounts.

\section{Author Disclosure Statement}

No competing financial interests exist.

\section{References}

1. Stolle D, Hooghe M, Micheletti M. Politics in the supermarket: political consumerism as a form of political participation. International Political Science Review 2005; 26:245-269.

2. Micheletti M. (2003) Political virtue and shopping: Individuals, consumerism, and collective action. New York: Palgrave, McMillan.

3. Arias C, Barreto I. Consumo ideológico: creencias sobre la política de seguridad democrática e imagen del presidente Alvaro Uribe Vélez. Universitas Psychologica 2009; 8: 749-760.

4. Conover MD, Gonçalves B, Flammini A, et al. Partisan asymmetries in online political activity. EPJ Data Science 2012; 1:6.

5. Bond RM, Fariss CJ, Jones JJ, et al. A 61-million-person experiment in social influence and political mobilization. Nature 2012; 489:295-298.

6. Gruzd A, Roy J. Investigating political polarization on twitter: a canadian perspective. Policy and Internet 2014; 6:28-45.

7. Garcia D, Abisheva A, Schweighofer S, et al. Ideological and temporal components of network polarization in online political participatory media. Policy and Internet 2015; 7:46-79.

8. Maruyama MT, Robertson SP, Douglas SK, et al. (2014) Hybrid media consumption: how tweeting during a televised political debate influences the vote decision. Proceedings of the 17th ACM Conference on Computer Supported Cooperative Work and Social Computing-CSCW. Baltimore, MD, pp. 1422-1432.

9. Park CS. Does Twitter motivate involvement in politics? Tweeting, opinion leadership, and political engagement. Computers in Human Behavior 2013; 29:1641-1648.

10. Minozzi W, Neblo MA, Esterling KM, et al. Field experiment evidence of substantive, attributional, and behavioral persuasion by members of Congress in online town halls Proceedings of the National Academy of Sciences United States of America 2015; 23:201418188.

11. Caldarelli G, Chessa A, Pammolli F, et al. A multi-level geographical study of Italian political elections from Twitter data. PloS One 2014; 9:e95809.

12. Grimmer J, Stewart BM. 2013. Text as data: the promise and pitfalls of automatic content analysis methods for political texts. Political Analysis 2013; 21:267-297.

13. Michalke M. (2014). Using the koRpus package for text analysis. https://cran.r-project.org/web/packages/koRpus/ vignettes/koRpus_vignette.pdf (accessed October 2016).

14. Turney PD, Pantel P. From frequency to meaning: vector space models of semantics. Journal of Artificial Intelligence Research 2010; 37:141-188.
15. Jurasfky D, Martin JH. (2014). Speech and language processing: an introduction to natural language processing, computational linguistics, and speech recognition. New York: Prentice-Hall.

16. Pak A, Paroubek P. Twitter as a corpus for sentiment analysis and opinion mining. LREC 2010; 1320-1326.

17. Sudhof M. Politics, Twitter, and information discovery: using content and link structures to cluster users based on issue framing. The Stanford Undergraduate Research Journal 2012; 11:67-76.

18. Bosco C, Patti V, Bolioli A. Developing corpora for sentiment analysis: the case of irony and senti-tut. IEEE Intelligent Systems 2013; 28:55-63.

19. Henry M, Mourifié I. Euclidean revealed preferences: testing the spatial voting model. Journal of Applied Econometrics 2013; 28:650-666.

20. Batlle M, Valdivieso JRP. Reformas políticas y partidos en Colombia: cuando el cambio es la regla. Politai: Revista de Ciencia Política 2013; 4:73-88.

21. Botero F. The legislative and executive elections in Colombia, 2014. Electoral Studies 2014; 30:1e5.

22. Palfrey TR, Poole KT. The relationship between information, ideology, and voting behavior. American Journal of Political Science 1987; 31:511-530.

23. Chirumbolo A, Leone L. Personality and politics: the role of the hexaco model of personality in predicting ideology and voting. Personality and Individual Differences 2010; 49:43-48.

24. Cha M, Haddadi H, Benevenuto F, et al. (2010) Measuring user influence in twitter: the million follower fallacy. Proceedings of the 4th International AAAI Conference on Weblogs and Social Media. Washington, DC, pp. 10-17.

25. Tumasjan A, Sprenger TO, Sandner PG, et al. (2010) Predicting elections with twitter: what 140 characters reveal about political sentiment. Proceedings of the 4th International AAAI Conference on Weblogs and Social Media. Washington, DC, pp. 178-185.

26. Jungherr A, Jürgens $P$, Schoen $H$. Why the pirate party won the German election of 2009 or the trouble with predictions: a response to Tumasjan, A., Sprenger, T.O., Sander, P.G., and Welpe, I.M. Predicting elections with twitter: what 140 characters reveal about political sentiment. Social Science Computer Review 2012; 30:229-234.

27. Correa A, Forero D. Incentivos al abstencionismo electoral por apatía en ciudadanos Bogotanos que nunca han votado. Suma de Negocios 2014; 5:105-114.

28. Gentry J. (2015) Package twitteR. www.cran.r-project.org/ web/packages/twitteR/twitteR.pdf (accessed July 2016).

29. Piantadosi ST. Zipf's word frequency law in natural language: a critical review and future directions. Psychonomic Bulletin and Review 2014; 21:1112-1130.

30. Jungherr A. Twitter use in election campaigns: a systematic literature review. Journal of Information Technology and Politics 2015; [Epub ahead of print]; DOI: 10.1080/ 19331681.2015.1132401

31. Hayfield T, Racine JS. Nonparametric econometrics: the np package. Journal of Statistical Software 2008; 27:1-32.

32. Ulloa FC, Carbó EP. The congressional and presidential elections in Colombia, 2002. Electoral Studies 2003; 22: 785-792.

33. Pachón M, Shugart MS. Electoral reform and the mirror image of inter-party and intra-party competition: the adoption of party lists in Colombia. Electoral Studies 2010; 29:648-660. 
34. Moreno E. Colombia's 2010 presidential and legislative elections. Electoral Studies 2011; 30:571-575.

35. Jungherr A, Schoen H, Jürgens, P. The mediation of politics through Twitter: an analysis of messages posted during the campaign for the german federal election 2013. Journal of Computer-Mediated Communication 2016; 21 : 50-68.

36. Wong FM, Tan C, Sen S, et al. (2013) Quantifying political leaning from tweets, retweets and retweeters. Seventh International AAAI Conference on Weblogs and Social Media (ICWSM) (20\% acceptance rate) Palo Alto, CA, pp. 640-649. Longer version in IEEE Transactions on Knowledge and Data Engineering.

37. Ramos-Serrano M, Gómez JDF, Pineda A. 'Follow the closing of the campaign on streaming': The use of Twitter by Spanish political parties during the 2014 European elections. New Media and Society 2016; [Epub ahead of print]; DOI: 10.1177/1461444816660730.
38. Ahmed S, Jaidka K, Cho J. The 2014 Indian elections on Twitter: a comparison of campaign strategies of political parties. Telematics and Informatics 2016; 33:1071-1087.

39. Taddy M. Multinomial inverse regression for text analysis. Journal of the American Statistical Association 2013; 108:755-770.

Address correspondence to: Dr. Juan C. Correa Facultad de Psicología Fundación Universitaria Konrad Lorenz Edificio Corpocentro Carrera 8 \#64-42, piso 4 Bogotá 110231 Colombia

E-mail: juanc.correan@konradlorenz.edu.co 